\title{
Insect diversity across an afro-tropical forest biodiversity hotspot
}

\author{
Jan Christian Habel ${ }^{1}$ (1) Elisabeth $\mathrm{Koc}^{2} \cdot$ Roland Gerstmeier $^{3} \cdot$ Axel Gruppe $^{3} \cdot$ Sebastian Seibold $^{2} \cdot$ Werner Ulrich $^{4}$
}

Received: 5 June 2020 / Accepted: 12 January 2021 / Published online: 10 February 2021

(c) The Author(s) 2021

\begin{abstract}
Tropical forests host a remarkable proportion of global arthropod diversity. Yet, arthropod communities living in tropical forests are still poorly studied, particularly for dry forests of Eastern Africa. The aim of this study was to analyse community structures, species richness and relative abundances of insects across a heterogeneous forest consisting of various forest types. We collected insects in the lower canopies with light traps across the Arabuko Sokoke forest, part of the East African coastal forest biodiversity hotspot in southeast Kenya. Sampling was conducted across three forest types and along the forest edge. In total we collected $>250,000$ individuals. We grouped these individuals into orders, and beetles into (sub) families. Representatives of the taxonomically well-known beetle families Cerambycidae, Tenebrionidae and Scolytinae were further determined to species level. We subsequently classified these groups into guilds according to their ecological requirements and life-histories. Relative abundances of arthropods strongly differed among taxonomic groups and forest types. Evenness was highest in the heterogeneous natural Brachystegia forest type. The mixed forest type and the forest edges showed intermediate degrees of evenness, while the structurally homogenous Cynometra forest showed comparatively low degrees of evenness.

Implications for insect conservation We found that taxonomic and guild compositions strongly differed among the forest types. Our findings reveal that structural heterogeneity of a forest is the major driver of insect diversity, community composition, and relative abundance. Our study underlines that the preservation of all three forest types is crucial to maintain the complete diversity of arthropods across all taxonomic groups.
\end{abstract}

Keywords Arthropods · Tropical forest · Biodiversity hotspot $\cdot$ Canopy $\cdot$ Species assemblies $\cdot$ Relative abundance $\cdot$ Guilds . Habitat structure $\cdot$ Forest conservation

\section{Introduction}

Tropical forests contain a major proportion of earth's biodiversity (Myers et al. 1988). The majority of invertebrate species living in tropical forests still await description (Stork

$\triangle$ Jan Christian Habel

Janchristian.habel@sbg.ac.at

1 Evolutionary Zoology, Department of Biosciences, University of Salzburg, 5020 Salzburg, Austria

2 Terrestrial Ecology Research Group, Department of Ecology and Ecosystem Management, School of Life Science Weihenstephan, Technische Universität München, 85354 Freising, Germany

3 Entomology Research Group, Department of Animal Sciences, School of Life Science Weihenstephan, Technische Universität München, 85354 Freising, Germany

4 Department of Ecology and Biogeography, Nicolaus Copernicus University Toruń, 87100 Toruń, Poland and Habel 2014). Previous studies have shown that particularly, forests rich in plant species and well-developed herb and shrub layers support a high insect diversity compared to homogeneous forests and tree plantations (Lucey and Hill 2012). In addition, intermediate levels of disturbance are known to increase biodiversity significantly, as well as natural disturbances such as clearings and windfalls (Alroy 2017).

Arthropod communities respond differently to the variation of biotic and abiotic conditions in ecosystems. Thus, it is impossible to derive general relationships between habitat heterogeneity and biodiversity, or responses of habitat disturbance to species richness (Ewers and Didham 2007). For example, sun-loving butterflies might respond positively to habitat disturbances inside a forest, while typical forest species might be negatively affected from such disturbances; Further, herbivorous insects might profit from herb- and shrub-layers, while species requiring open bare soils might be negatively 
affected from overgrowth (Hayes et al. 2009). In consequence, we assume that insect assemblies vary across forests, depending on forest type, vegetation structure and abiotic conditions.

The East African dry coastal forest consists of at least three different forest types (Murithi and Kenyon 2002). These forest types differ in plant species composition and diversity and soil conditions (Murithi and Kenyon 2002). Thus, the East African dry coastal forest creates a mix of different forest types, which accelerates biodiversity, as shown for various taxa, such as snails (Lange and Mwinzi 2003) and butterflies (Habel et al. 2018). In consequence, this forest is part of a global biodiversity hotspot (Myers et al. 2000). Anthropogenic activities such as the transformation of forest into plantations of exotic trees and agricultural land produced multiple forest edges and caused severe disturbances inside the remaining forest patches (Habel et al. 2017).

To explore the diversity and abundance of invertebrates among forest types, we sampled arthropods in the lower tree canopy at about $8 \mathrm{~m}$ height throughout all three forest types of the Arabuko Sokoke coastal forest. In addition, we conducted sampling along forest edges, to test for potential effects from habitat disturbance to arthropod diversity and community composition (e.g. Arroyo-Rodríguez et al. 2017). Sampling was conducted during the dry season. We grouped all individuals into orders, beetles into families and sub-families, and representatives of the taxonomically well known beetle families Cerambycidae, Tenebrionidae and Scolytinae were further determined individuals to species level. We assigned all taxa into ecological guilds. Based on these data we will answer the following questions:

(i) Do arthropod communities, ecological guild compositions, and relative abundances of taxa differ among the habitat types?

(ii) Do forest edges provide a diverse arthropod community in comparison to forest interior?

(iii) Which conclusions can we draw from these findings for the conservation of forests?

\section{Material and methods}

\section{Study area and forest types}

The study area covers the East African dry coastal Arabuko Sokoke forest in south-eastern Kenya. This $6 \mathrm{~km}^{2}$ large forest remnant harbors a large number of endemic plant and animal species (Matiku et al. 2013; Marchese 2015). The forest consists of at least three forest types (Murithi and Kenyon 2002). The distribution of these forest types follows particular soil conditions, which subsequently impact species composition of plants, and thus shapes habitat structures and animal communities living therein (Lange and Mwinzi 2003; Habel et al. 2018). The Cynometra forest is restricted to infertile laterite soils. This forest is dense, homogenous and mono-layered (Kanga 2002) and dominated by Cynometra webberi, Brachylaena huillensis and Manikara sulcata. The Brachystegia forest grows on well-drained silica sands. This forest type consists of a well-developed herb and shrub layer with many flowering plants (Oyugi et al. 2007), and is dominated by Brachystegia spiciformis and Hymenaea verrucosa trees. The mixed forest grows on grey colored Pleistocene lagoonal sands and clays, and consists of a mix of Afzelia quanzensis, Hymenaea verrucosa, Combretum schumannii and Manilkara sansibarensis trees. This forest type is multilayered with large trees and a dense thicket (Glenday 2008). As a fourth habitat type we considered the forest edge. For this we selected the border between mixed forest and agricultural land, which forms an abrupt edge between dense forest and open land with fields, housings and gardens. The Arabuko Sokoke forest dramatically shrinked in size during the past decades, and suffers under the deterioration of habitat quality across all three forest types, due to logging of hardwood timber, the production of charcoal, and intense collection of dead wood (Cuadros-Casanova et al. 2018). The location of our study area and the distribution of forest types is displayed in Online Appendix S1.

\section{Data collection}

Arthropod sampling was conducted across three forest types, and along the forest edge of the Arabuko Sokoke coastal forest with light traps equipped with blue, green and UV LEDs, which were attached to four panes $(10 \times 30 \mathrm{~cm}$ each $)$ of acrylic glass. A collecting jar underneath was filled with ethanol. A power bank provided electricity for one night $(>12 \mathrm{~h})$. We installed light traps in the lower canopies about $8 \mathrm{~m}$ above ground. Sampling was done at 9 locations for each of the three forest types, Brachystegia forest, Cynometra forest, mixed forest, and at 9 locations along the forest edge (in total 36 sampling sites). Arthropod sampling was repeatedly conducted during two nights at each sampling site $(2 \times 36=72)$. Each trap was activated from $5 \mathrm{pm}$ to $7 \mathrm{am}$. We emptied the traps each morning and changed the batteries. Sampling was conducted during a three weeks sampling campaign (28.02.2017 until 15.03.2017). The UV LEDs were placed in the dense leaf canopy. Therefore the radiant power of the LEDs were limited in space. To reduce potential spatial autocorrelation, distances among traps were at least $200 \mathrm{~m}$, and the UV LEDs were placed so that the light of the neighboring lamp was not visible (see Horak 2013). 


\section{Taxonomic determination}

All individuals were sorted to taxonomic orders (namely Apocrita, Blattodea, Caelifera, Coleoptera, Diptera, Embioptera, Formicidae, Hemiptera, Lepidoptera, Mantodea, Neuroptera, Psocoptera). Due to the fact that most beetles are taxonomically well described, we further assigned this group to family and subfamily level (namely Laemophloeide, Anthicidae, Carabidae, Tenebrionidae, Curculionidae, Cantharidae, Cleridae, Staphylinidae, Elateridae, Scarabaeoidae, Brentidae, Cerambycidae, Scolytidae) according to literature (Delvare and Aberlenc 1989; Bährmann 1995; Lawrence and Ślipiński 2013) and expert knowledge (RG, AG, SS). Species were further identified for the well known (sub)families Cerambycidae, Tenebrionidae and Scolytinae by expert taxonomists (for names see acknowledgement). A compilation of all individuals and taxa found are given in Online Appendix S2-S4, for orders, beetle (sub-)families, and beetle species, respectively.

\section{Guilds}

We have selected guilds that are directly related to habitat structures, and thus reflect species' responses to habitat conditions (see Simberloff and Dayan 1991). We grouped orders and (sub)families as follows: Type of development (hemimetabolic vs holometabolic); Consumer guilds (consumers of first order i.e. phytophagous and detrivorous mainly; consumers of second order i.e. predators mainly, and parasitoids mainly); And, dead-wood dependency. Guild assignments were conducted based on the characteristics represented by the majority of representatives of a respective order i.e. (sub) family. Since a clear ecological allocation was not possible in some cases (phytophagous and detrivorous), those were lumped together. Classification was done according to literature (Stork 1987; Schmidl and Bussler 2004; Leksono et al. 2005), and expert knowledge (RG, AG, SS). We have to tolerate a certain degree of inaccuracy here and will take this into account when interpreting and discussing our results. Guild classifications are given in Online Appendix S2, S3.

\section{Statistics}

For orders, (sub) families and species, we constructed taxon $\times$ sample matrices containing the numbers of individuals per taxon and sample. As the total number of individuals among taxa differed strongly, we calculated relative abundances per sample, by dividing the number of individuals through the total sample size for each taxon. Total relative abundances per sample refer then to the relative abundances summed over all taxa. We note that this normalization means that all taxa had the same weight in our analysis. We used nonmetric multidimensional scaling (NMMDS) with Gower dissimilarities to visualize the differences in community composition. Finally, we used one-way ANOVA with posthoc Tukey tests and PERMANOVA to assess differences in relative abundance of taxa (orders, (sub)families, species) and groups of guilds among the four habitat types (Cynometra forest, Brachystegia forest, mixed forest, forest edge). Calculations were performed with the programs Statistica 12.0 and Past 4.01.

\section{Results}

\section{Orders}

In total, we collected $>250,000$ individuals of arthropods across all four habitat types. Relative abundances of all taxa differed significantly among the four habitat types (Fig. 1). Highest relative abundance was found in Brachystegia forest (post hoc ANOVA Tukey test: all pairwise $\mathrm{P}<0.05$ ). Lowest relative abundance was found in Cynometra forest. Post hoc Tukey tests did not show significant differences between Cynometra forest, mixed forest, and forest edge (Fig. 1). Patterns of relative abundances in different habitat types varied among orders (Fig. 2a). Again, most taxa achieved highest relative abundances (namely Formicidae, Araneae, Apocrita, Heteroptera, Diptera, Neuroptera) in Brachystegia forest, while relative abundances of most orders assessed in Cynometra forest was comparatively low (Fig. 2a). In contrast, Blattodea and Psocoptera showed highest relative abundances in the mixed forest. Comparatively high relative abundances of Coleoptera and Diptera was found along the forest edge (Fig. 2a). For the Cynometra forest we obtained very low levels of relative abundances, except for the order Apocrita (Fig. 2a). For Lepidoptera we found no significant differences of relative abundance among all four habitat types (Fig. 2a). These results are corroborated by the ordination analyses, that separated particularly the arthropod communities of the Brachystegia forest according to the first

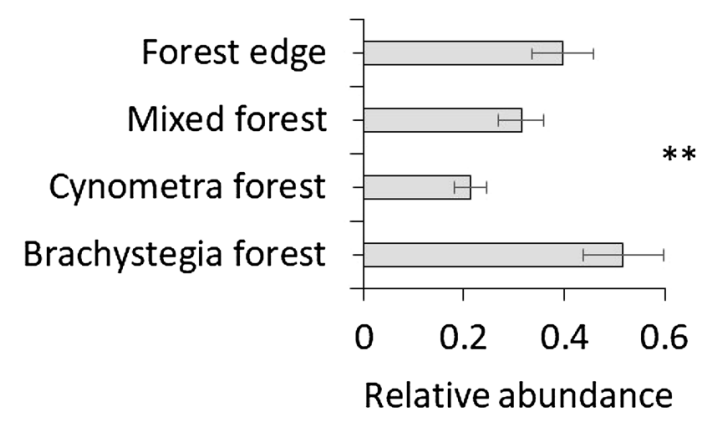

Fig. 1 Relative abundances of all studied arthropod taxa in four habitat types. Error bars denote parametric standard errors. Parametric one-way ANOVA between forest types: $* * \mathrm{P}_{3,32}<0.01$ 


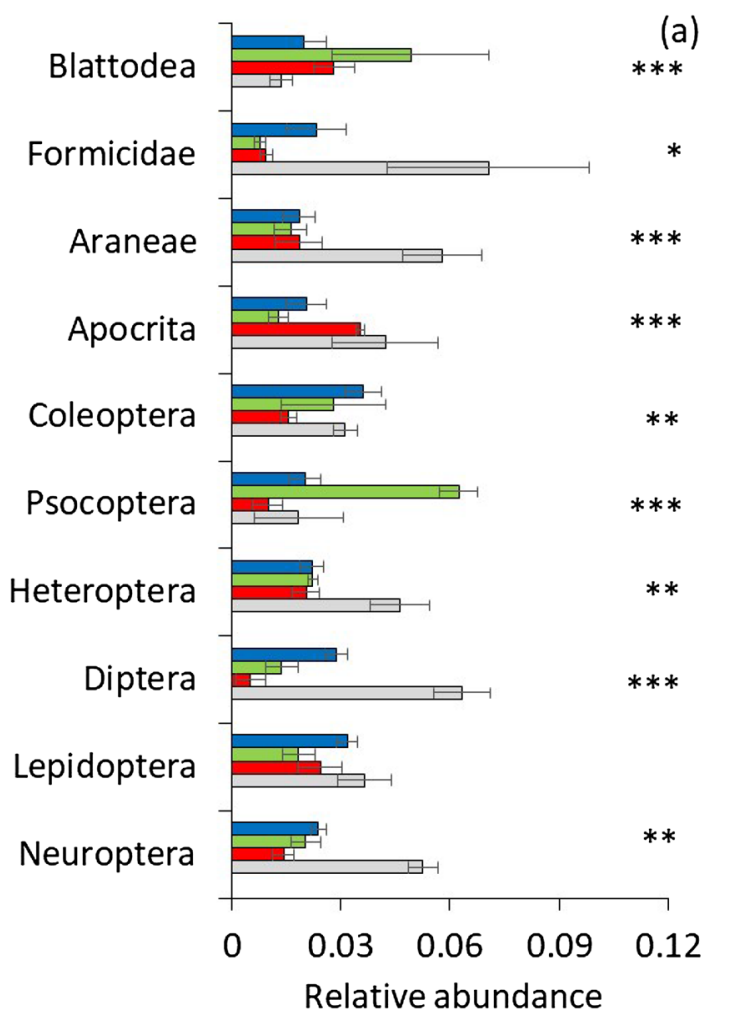

Fig. 2 Relative abundances of orders of arthropods a and of beetle families $\mathbf{b}$ assessed in four habitat types (blue bars: forest edge, green: mixed forest, red: Cynometra forest, grey: Brachystegia for-

NMMDS axis (Fig. 3a). With respect to spider families, the Brachystegia and the Cynometra forest were most different in community composition (Fig. 3b).

\section{Beetle (sub) families and beetle species}

When considering the (sub)families of beetles, we found significant differences among the four habitat types (Fig. 2b). Particularly Cerambycidae, Curculionidae and Tenebrionidae were most abundant in Brachystegia forest (Fig. 2b), while Scarabaeoidea and Laemophloeidae occurred in comparatively high numbers in the mixed forest (Fig. 2b). Cynometra forest showed again lowest relative abundances for most beetle (sub)families, except for Elateridae, Cantharidae, Staphylinidae and Tenebrionidae (Fig. 2b). NMMDS separated the Brachystegia forest from the three other habitat types (Fig. 3c). Arthropod communities of the Brachystegia forest, forest edge, and mixed forest even did not overlap in ordination space (Fig. 3c). The arthropod community of Cynometra forest appeared to be most homogeneous in composition (Fig. 3c).

Overall, we collected 86 individuals (19 species) of cerambycid beetles, 325 individuals ( 31 species) of scolytinae beetles, and 1620 individuals ( 36 species) of tenebrionid

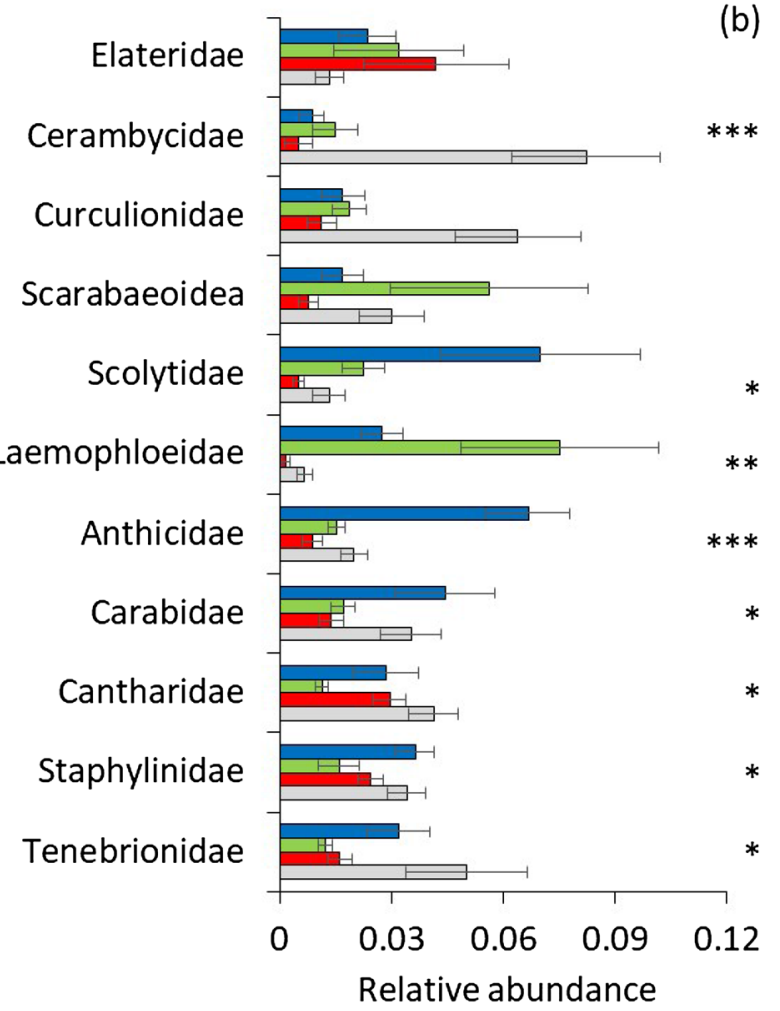

est).. Error bars denote parametric standard errors. Apocrita exclude ants. Parametric one-way ANOVA between forest types: $* \mathrm{P}_{3,32}<0.05$, $* * \mathrm{P}_{3,32}<0.01$. $* * * \mathrm{P}_{3,32}<0.001$. (Color figure online)

beetles. The cerambycid community composition based on species abundances significantly differed between the four habitat types (one-way PERMANOVA P $<0.001$ ). NMMDS demonstrated clear compositional differences between the four habitats with respect to species composition (Fig. 3d). The Brachystegia forest exhibited also the widest compositional variation (Fig. 3d). In the Brachystegia forest we sampled 66 individuals $(76 \%)$ of the cerambycids, while the three other forest types were represented by only 20 individuals (one-way ANOVA $\mathrm{P}_{3,32}<0.001$ ). We found significant differences between relative abundances and forest types in scolytid species (one-way ANOVA $\mathrm{P}_{3,32}=0.01$ ). 205 of the 320 scolytid individuals were captured at the forest edge. Tenebrionidae (one-way ANOVA $\mathrm{P}_{3,32}=0.03$ ) were least abundant in the mixed forest.

\section{Guilds}

Holometabolic insects showed highest relative abundances in the Brachystegia forest, and similar relative abundances in the three other habitat types (Fig. 4). Hemimetabolic insects showed similar relative abundances in Brachystegia, mixed forest and at the forest edge, but were least abundant in Cynometra forest (Fig. 4). Within our two trophic groups we found 
Fig. 3 The first two axes of non metric multidimensional scaling (Gower dissimilarities) separated arthropod orders (a), spider families (b), beetle families (c), and cerambycid species (d) of the four habitats: green: Brachystegia forest (B); blue: Cynometra forest (C); red: forest edges (E); yellow: mixed forest $(\mathrm{M})$. Stress values $(\mathbf{a})$ : $\mathrm{s}=0.23 ;(\mathbf{b}): \mathrm{s}=0.16 ;(\mathbf{c}) \mathrm{s}=17$, (d) $\mathrm{s}=0.19$. (Color figure online)
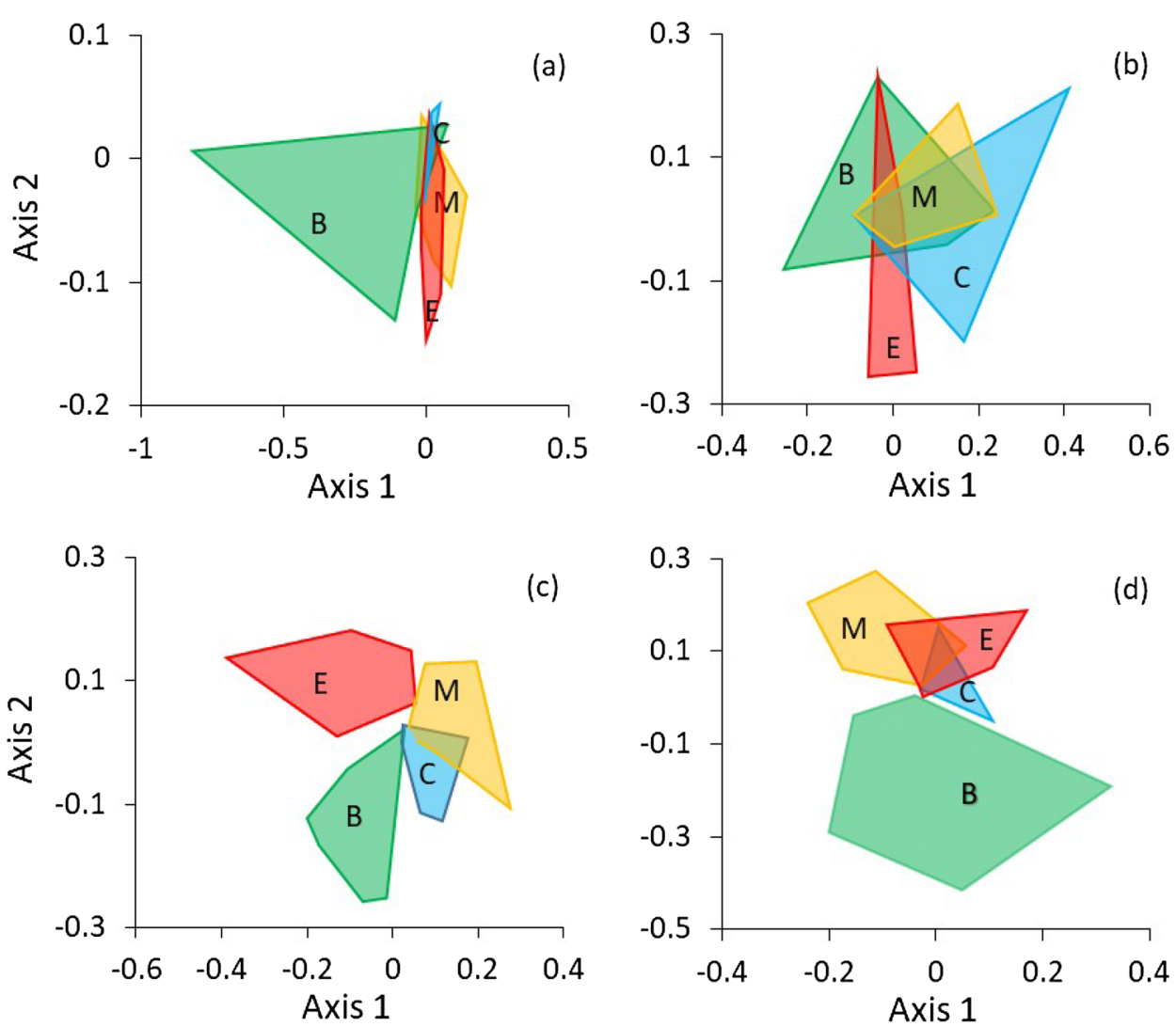

no significant differences for first order consumers, but higher relative abundances of second order consumers in Brachystegia forest than in the other forest types and at the forest edge (Fig. 4). Dead-wood dependency showed no significant differences among taxa and habitat types.

Beetle (sub)families grouped according to the major consumer guilds and exhibited significant differences in relative abundances among the four habitat types (see Fig. 5). Mycetophagous beetles showed highest relative abundances in the mixed forest (Fig. 5), while phytophagous beetles dominated in the Brachystegia forest (Fig. 5). Xylophagous beetles were most abundant at the forest edge (Fig. 5). There were no clear correlations in relative abundances between the trophic guilds, except for omnivores - xylophages (Spearman's $r=0.62$, permutation $\mathrm{P}<0.01$ ) and the saprophages - phytophages combinations (Spearman's $\mathrm{r}=0.53$, permutation $\mathrm{P}<0.05$ ).

\section{Discussion}

We found highest relative abundances for most orders and (sub)families in the Brachystegia forest and lowest values in the Cynometra forest, while mixed forest and forest edge showed intermediate levels of relative abundances for most taxa. The results were corroborated by the ordination analyses that point to strong compositional differences

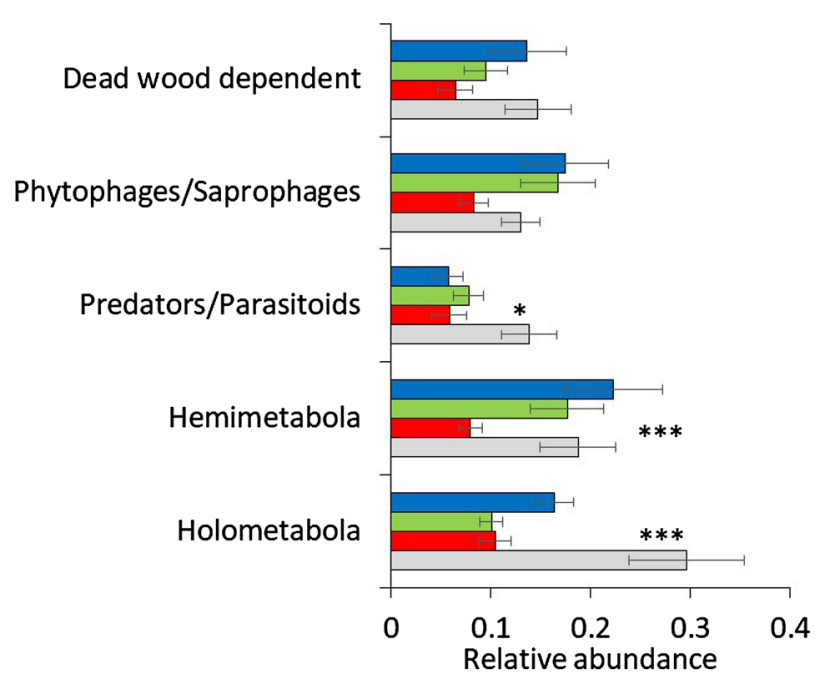

Fig. 4 Relative abundances of orders assigned to four groups of guilds across four habitat types (blue bars: forest edge, green: mixed forest, red: Cynometra forest, grey: Brachystegia forest). Error bars denote parametric standard errors. Parametric one-way ANOVA: $* \mathrm{P}_{3,32}<0.05 ; * * * \mathrm{P}_{3,32}<0.001$. (Color figure online)

between the forest types and the largest ordination spaces for the Brachystegia forest. 


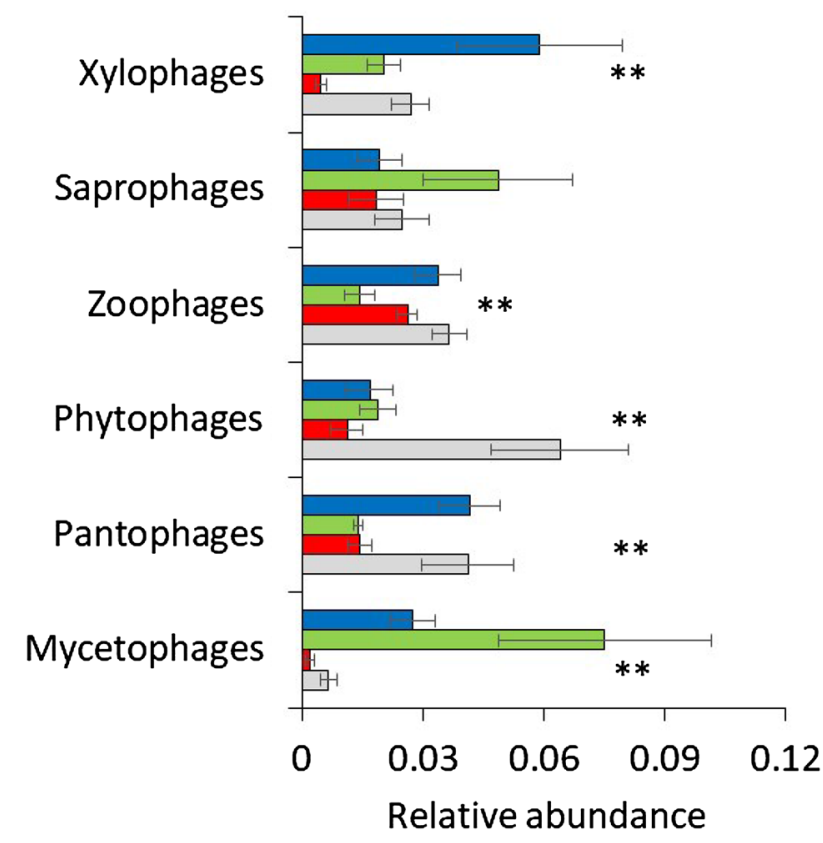

Fig. 5 Relative abundances of Coleoptera families and subfamily sorted into trophic groups across four habitat types (blue bars: forest edge, green: mixed forest, red: Cynometra forest, grey: Brachystegia forest). Error bars denote parametric standard errors. Parametric oneway ANOVA: $* * \mathrm{P}_{3,32}<0.01$. (Color figure online)

Interestingly, for some groups we found divergent trends. For example, representatives of the orders Blattodea and Psocoptera showed highest relative abundances in the mixed forest, while Coleoptera, Lepidoptera and Diptera were very abundant along the forest edge. These contrasting order and family specific trends might be responses to local biotic and abiotic conditions, such as the availability of specific (micro) habitats and resources in the respective forest types (Donsen and Fahrig 1997; Devictor et al. 2008). For example, most representatives of the orders Blattodea and Psocoptera depend on comparatively humid conditions near the ground, as found in the mixed forest, and mainly occur in association with deadwood or are found under foliage, foraging on algae, lichens, fungi and various plant products (Bell et al. 2007). Similarly, humid conditions and the availability of deadwood and litter also support saprophagous and mycetophagous beetles (Topp et al. 2006). This is also confirmed by our results for the Cynometra forest. This forest type is growing on grey colored Peistocene clays and thus provide higher soil moisture than the sandy soils of the Brachystegia forest (Kanga 2002; Kagema et al. 2016). Most of the other taxa, such as Formicidae, Araneae, Heteroptera, Diptera and Neuroptera showed highest relative abundances in the Brachystegia forest. This forest type provides high plant diversity consisting of trees and a rich shrub and herb layer, as well as glades and a large variety of nectar sources (Oyugi et al. 2007). In consequence, phytophagous species, such as
Heteroptera, and some Diptera and Neuroptera particularly benefit from this high level of plant diversity.

Different preferences of species for certain forest types, and differences in community composition underline that taxa are strongly associated with specific abiotic and biotic conditions and resources. Despite the low taxonomic resolution of identification and the related uncertainty when assigning taxa to guilds, we found significant differences among the forest types based on the groups of guilds applied here. Our results underline that using ecological species information might help to better identify the mechanisms explaining the differences between forest types (LebrijaTrejos et al. 2010; Habel et al. 2019).

Our data collected along the forest edge show highest relative abundances for Coleoptera (especially Scolytinae, Anthicidae, Carabidae and Staphylinidae). When considering our guild classification we found highest relative abundances for xylophagous and pantophagous beetles along forest edges. Such transition zones provide higher solar radiation than a closed canopy forest. This significantly promotes a rich herb layer and a rich variety of nectar sources (Zellweger et al. 2020). Many insect groups, including wood-inhabiting beetles, benefit from the availability of these resources and the higher temperatures (Wermelinger et al. 2007; Lehnert et al. 2013; Seibold et al. 2016). A large proportion of beetles, especially pantophagous ones, successfully develop on crops in agricultural fields as well as in gardens. We also found comparatively high levels of relative abundance for representatives of the orders Lepidoptera and Diptera along the forest edge. This goes in line with previous studies on butterflies, which were observed inside and along forest edges of the Arabuko Sokoke forest (Habel et al. 2018). The authors found that butterfly communities along the forest edges were comparatively diverse, consisting of both, typical forest specialist species intermixed with species occurring in open landscapes. However, we have to consider that even if the diversity of species in the interior of an intact forest is less than at the forest edge, most typical forest specialists occur largely restricted to the forest interior and can only rarely found along the forest edge (Magura et al. 2001).

\section{Conclusion}

In conclusion, our results showed that relative abundances vary among orders and strongly rely to forest types (as also indicated for other taxonomic groups, such as butterflies, Habel et al. 2017). This trend is confirmed by all the parameters determined, as species richness, relative abundance, and community structure (based on relative abundances and guilds). This indicates that the preservation of all three forest types is crucial to hold the entire diversity of this East African coastal forest biodiversity hotspot. 
Although our results are very clear, we would like to pointing out the weaknesses of this study. 1. Potential autocorrelation: We have to consider here that flying insects are able to disperse over large distances, but attraction to light appears to be limited to only small radii (Truxa and Fiedler 2012). We note that our study design leads to a certain degree of spatial non-independence between samples. However, this type of spatial autocorrelation serves to account for the environmental variably not related to our study questions, which might influence the comparisons between arthropod communities. Further variance analyses even assume that the within treatment variability is low in comparison to the between treatment, which means for spatial samples that they are spatially autocorrelated. 2 . Comparatively rough classification of taxa into distinct guilds: This might blur potential community structures (as already discussed above). 3. Effects from seasonality, which we do not consider here: The patterns obtained in our study provide a snap-shot taken during the end of a dry season within a 3 weeks field campaign. The obtained community structures may vary over seasons in the wake of resource availability and taxon-specific phenologies and responses. Previous studies indicate significant changes of vegetation structures in tropical forests over seasons (Guan et al. 2013), which may impact relative abundances and distribution patterns of animal species (Basset 2001; Seyfulina and De Bakker 2008; Medina and Lopes 2014; Habel et al. 2018). Therefore, the same study might produce a different picture at different time points (the strongly pronounced rainy and dry seasons in this region). 4. Our results refer to data collected during night, and thus do not consider the taxonomic repertoire of taxa, which are active during day. Thus, results based on daily-active species might create a diverging picture. Thus, our data tells only part of the story. Nevertheless, the fact that all parameters assessed showed identical structures and trends confirm a high informative value of our collected data.

Supplementary Information The online version contains supplementary material available at https://doi.org/10.1007/s10841-021-00293-z.

\begin{abstract}
Acknowledgements We thank Jose Rangel, Lynn Njeri Njuguna and Noreen Mutoro for data collection in the field. We thank the following taxonomists for the identification of taxa: Karl Adlbauer (Graz, Austria) (Cerambycidae), Heiko Gebhardt (Tübingen, Germany) (Scolytinae), Wolfgang Schawaller (Stuttgart, Germany) (Tenebrionidae). We thank Pwani University and the Kenyan Wildlife Service for fruitful collaboration, and the German Academic Exchange Service for funding. W.U. acknowledges support from an NCU institutional grant. We thank for fruitful comments on a first version of this article by reviewers and the editor.
\end{abstract}

Funding Open Access funding provided by Paris Lodron University of Salzburg.

\section{Compliance with ethical standards}

Conflict of interest There exist no potential conflicts of interest.

Ethical approval Sampling of arthropods was conducted in collaboration with the National Museums of Kenya and Pwani University Kenya, under respective research permits.

Informed consent All raw data of this article are available to the public.

Open Access This article is licensed under a Creative Commons Attribution 4.0 International License, which permits use, sharing, adaptation, distribution and reproduction in any medium or format, as long as you give appropriate credit to the original author(s) and the source, provide a link to the Creative Commons licence, and indicate if changes were made. The images or other third party material in this article are included in the article's Creative Commons licence, unless indicated otherwise in a credit line to the material. If material is not included in the article's Creative Commons licence and your intended use is not permitted by statutory regulation or exceeds the permitted use, you will need to obtain permission directly from the copyright holder. To view a copy of this licence, visit http://creativecommons.org/licenses/by/4.0/.

\section{References}

Alroy J (2017) Effects of habitat disturbance on tropical forest biodiversity. Proc Nat Acad Sci 114:6056-6061

Arroyo-Rodríguez V, Melo FPL, Martínez-Ramos M, Bongers F, Chazdon RL, Meave JA, Norden N, Santos BA, Leal IR, Tabarelli M (2017) Multiple successional pathways in human-modified tropical landscapes: new insights from forest succession, forest fragmentation and landscape ecology research. Biol Rev 92:326-340

Bährmann R (ed) (1995) Bestimmung wirbelloser Tiere: Bildtafeln für zoologische Bestimmungsübungen und Exkursionen, 3rd edn. Gustav Fischer Verlag, Stuttgart - Jena, p 362

Basset Y (2001) Invertebrates in the canopy of tropical rain forests How much do we really know? Plant Ecol 153:87-107

Bell WJ, Roth LM, Nalepa CA (2007) Cockroaches: ecology, behavior, and natural history. The Johns Hoppkins University Press, Baltimore

Cuadros-Casanova I, Zamora C, Ulrich W, Seibold S, Habel JC (2018) Empty forests: Safeguarding a sinking flagship in a biodiversity hotspot. Biodiv Conserv 27:2495-2506

Delvare G, Aberlenc H-P (1989) Les insects d'Afrique et d'Amerique tropicale: Cles pur la reconnaissance des Familles. Centre de cooperation internationale en recherche agronomique pour le developpement, Montpellier, p 298

Devictor V, Juillard R, Jiguet F (2008) Distribution of specialist and generalist species along spatial gradients of habitat disturbance and fragmentation. Oikos 117:507-514

Donsen ID, Fahrig L (1997) Response of generalist and specialist insect herbivores to landscape spatial structure. Land Ecol 12:185-197

Glenday J (2008) Carbon storage and emissions offset potential in an African dry forest, the Arabuko-Sokoke Forest, Kenya. Env Monitoring Ass 142:85-95

Guan K, Wolf A, Medvigy D, Caylor KK, Pan M, Wood EF (2013) Seasonal coupling of canopy structure and function in African tropical forests and environmental controls. Ecosphere 4:1-21

Habel JC, Cuadros Casanova IC, Zamora C, Teucher M, Hornetz B, Shauri H, Mulwa RK, Lens L (2017) East African coastal forest under pressure. Biodiv Conserv 26:2751-2758 
Habel JC, Seibold S, Ulrich W, Schmitt T (2018) Seasonality overrides differences in butterfly species composition between natural and anthropogenic forest habitats. Anim Conserv 21:405-413

Habel JC, Tobias JA, Fischer C (2019) Movement ecology of Afrotropical birds: Functional traits provide complementary insights to species identity. Biotropica 51:894-902

Hayes L, Mann DJ, Monastyrskii AL, Lewis OT (2009) Rapid assessments of tropical dung beetle and butterfly assemblages: contrasting trends along a forest disturbance gradient. Insect Conserv Div 2:194-203

Horak J (2013) Effect of site level environmental variables, spatial autocorrelation and sampling intensity on Arthropod communities in an ancient temporate lowland woodland area. PlosOne 8:e81541

Kagema F, Kalama A, Onyango T (2016) Avifauna and flora report for Arabuko Sokoke forest (ASF). Important Bird Areas in Kenya, Nature Kenya

Kanga EM (2002) A conservation and recovery plan for the Ader's Duiker Cephalophus adersi in Arabuko Sokoke forest. Kenya, Arabuko-Sokoke Forest Management Team

Lange CN, Mwinzi M (2003) Snail diversity, abundance and distribution in Arabuko Sokoke forest, Kenya. African J Ecol 41:61-67

Lawrence JF, Ślipiński A (2013) Australian beetles - morphology, classification and keys. CSIRO Publishing, Collingwood 2013:561

Lebrija-Trejos E, Pérez-García EA, Meave JA, Bongers F, Poorter L (2010) Functional traits and environmental filtering drive community assembly in a species-rich tropical system. Ecology 91:386-398

Lehnert LW, Bässler C, Brandl R, Burton PJ, Müller J (2013) Conservation value of forests attacked by bark beetles: Highest number of indicator species is found in early successional stages. J Nat Conserv 21:97-104

Leksono AS, Takada K, Koji S, Nakagoshi N, Anggraeni T, Nakamura $\mathrm{K}$ (2005) Vertical and seasonal distribution of flying beetles in a suburban temperate deciduous forest collected by water pan trap. Insect Sci 12:199-206

Lucey JM, Hill JK (2012) Spillover of insects from rain forest into adjacent oil palm plantations. Biotropica 44:368-377

Magura T, Tóthmérész B, Molnár T (2001) Forest edge and diversity: carabids along forest-grassland transects. Biodiv Conserv 10:287-300

Marchese C (2015) Biodiversity hotspots: A shortcut for a more complicated concept. Global Ecol Conserv 3:297-309

Matiku P, Caleb M, Callistus O (2013) The impact of participatory forest management on local community livelihoods in the ArabukoSokoke forest. Kenya Conserv Soc 11:112
Medina AM, Lopes PP (2014) Seasonality in the dung beetle community in a Brazilian tropical dry forest: Do small changes make a difference? J Insect Sci 14:1-11

Murithi S, Kenyon W (2002) Conservation of biodiversity in the Arabuko Sokoke forest, Kenya. Biodiv Conserv 11:1437-1450

Myers N (1988) Threatened biotas: Hot spots in tropical forests. Environmentalist 8:187-208

Myers N, Mittermeier RA, Mittermeier CG, Da Fonseca GA, Kent J (2000) Biodiversity hotspots for conservation priorities. Nature 403:853-858

Oyugi J, Brown JS, Whelan CJ (2007) Effects of human disturbance on composition and structure of Brachystegia woodland in ArabukoSokoke forest, Kenya. Afr J Ecol 46:374-383

Schmidl J, Bussler H (2004) Ökologische Gilden xylobionter Käfer Deutschlands. Naturschutz und Landschaftsplanung 36:202-218

Seibold S, Bässler C, Brandl R, Büche B, Szallies A, Thorn S, Ulyshen MD, Müller J (2016) Microclimate and habitat heterogeneity as the major drivers of beetle diversity in dead wood. J Appl Ecol 53:934-943

Seyfulina RR, De Bakker D (2008) Linyphiid spiders (Araneae, Linyphiidae) from African forest canopies. Revista Iberica de Arachnologia 15:67-79

Simberloff D, Dayan T (1991) The guild concept and the structure of ecological communities. Ann Rev Ecol Sys 22:115-143

Stork NE (1987) Guild structure of arthropods from Bornean rain forest trees. Ecol Entomol 12:219-226

Stork NE, Habel JC (2014) Can biodiversity hotspots protect more than tropical forest plants and vertebrates? J Biogeo 41:421-428

Topp W, Kappes H, Kulfan J, Zach P (2006) Litter-dwelling beetles in primeval forests of Central Europe: Does deadwood matter? J Insect Cons 10:229-239

Truxa C, Fiedler K (2012) Attraction to light- from how far do moths(Lepidoptera) return to weak artificial sources of light? Europ J Entomol 5759:77-84

Wermelinger B, Flückiger PF, Obrist MK, Duelli P (2007) Horizontal and vertical distribution of saproxylic beetles (Col., Buprestidae, Cerambycidae, Scolytinae) across sections of forest edges. J Appl Entomol 131:104-114

Zellweger et al (2020) Forest microclimate dynamics drive plant responses to warming. Science 368:772-775

Publisher's Note Springer Nature remains neutral with regard to jurisdictional claims in published maps and institutional affiliations. 